\title{
A AULA DE LEITURA E A LEITURA NA AULA
}

\author{
MARIA ELIZABETE SOUZA COUTO
}

\begin{abstract}
Graduada em Pedagoga pela Federação das Escolas Superiores de Ilhéus e Itabuna/FESPI, Mestrado em Educação pela UFBA/UESC, Doutorado em Educação pela UFSCar/ São Paulo. Atua na Universidade Estadual de Santa Cruz/UESC, na pesquisa, ensino e extensão, nas áreas: formação de professores, alfabetização e prática pedagógica. ORCID: https://orcid.org/0000-0002-0026-5266 E-mail: melizabetesc@gmail.com
\end{abstract}

\section{JAMILE BARROS ANDRADE}

Graduada em Pedagogia pela Universidade Estadual de Santa Cruz - UESC, Mestre em Educação no Programa de Pós-Graduação Formação de Professores da Educação Básica/PPGE - Mestrado Profissional em Educação/UESC. Especialista em Psicopedagogia, Coordenadora Pedagógica da Escola CAIC Jorge

Amado em Itabuna/BA. Atua na formação de professores/e na alfabetização. ORCID: https://orcid. org/0000-0003-1544-5232. E-mail: jamile.pab@gmail.com

\section{RESUMO}

Este artigo tem como objetivo analisar como as professoras-alfabetizadoras estabelecem as relações entre os estudos sobre leitura nas sessões de formação e em sala de aula. Tivemos como objeto de estudo a leitura em sala de aula. A pesquisa realizada teve uma abordagem qualitativa, com a participação de duas professoras-alfabetizadoras. Para a produção do material empírico utilizamos fichas de observação nas sessões de formação e nas aulas das 
professoras-alfabetizadoras e entrevistas. Na formação houve o desenvolvimento de práticas de leitura, ora centradas na Orientadora de Estudos, ora nos professores-alfabetizadores, o mesmo acontecendo em sala de aula. Como produto dessa pesquisa, planejamos sequências didáticas, que foram realizadas em sala de aula com o objetivo de desenvolver a compreensão leitora, sinalizando possibilidades do uso das estratégias antes, durante e depois da leitura. Nas sessões de formação eram vivenciadas práticas de leitura, no entanto, não havia o momento para fazer as reflexões/mediações que permitissem uma ampliação do seu conhecimento, visto que reproduziam, no trabalho pedagógico, uma relação ingênua sobre a leitura. Por fim, a formação ainda não rompeu com a ideia de que a leitura se aprende apenas com e pelo prazer, sem enfatizar a necessidade de um trabalho com as estratégias e práticas de leitura para desenvolver as competências leitoras, tanto nos professores quanto em seus alunos.

Palavras-chave: Leitura. Formação. Prática em sala de aula.

\section{THE CLASSROOM OF READING AND READING IN THE CLASSROOM}

This article aims to analyze how literacy teachers establish relationships between reading studies in the training sessions and in the classroom. We had as object of study the reading in the classroom. The research carried out had a qualitative approach, with the participation of two literacy teachers. For the production of the empirical material we used observation sheets in the training sessions and in the classes of the teachers-literacy teachers and interviews. In the training there was the development of reading practices, now focused on the Study Advisors, or on the teacher-literacy teachers, the same happening in the classroom. As a product of this research, we planned didactic sequences, which were carried out in the classroom in order to develop reading comprehension, signaling possibilities of using strategies before, during and after reading. In the training sessions, reading practices were experienced, however, there was not the moment to make the reflections / mediations that allowed an amplification of their knowledge, since they reproduced, in the pedagogical work, a naive relation about the reading. Finally, the training has not yet broken with the idea that reading is only learned with and for pleasure, without emphasizing the need to work with reading strategies and practices to develop reading skills, both in teachers and in their students.

Keywords: Reading. Formation. Practice in the classroom.

\section{LA CLASE DE LECTURA Y LA LECTURA EN LA CLASE}

En este artículo se pretende analizar cómo los maestros, alfabetizadores establecer la relación entre los estudios sobre la lectura en las sesiones de entrenamiento y en el aula. Hemos tenido como objeto de estudio la lectura en el aula. La investigación tuvo un enfoque cualitativo, con la participación de dos profesores, maestros de alfabetización. Para la producción de material empírico utilizamos formularios de observación en las sesiones de entrenamiento y clases de maestros, alfabetizadores y entrevistas. En el entrenamiento no fue el desarrollo de las prácticas de lectura, ahora centradas en Estudios de orientación, ahora en maestro-alfabetización, lo mismo sucedió en el aula. Como este producto de la investigación, 
tenemos la intención secuencias didácticas, que tuvieron lugar en el aula con el fin de desarrollar la comprensión lectora, las posibilidades de utilizar las estrategias antes, durante y después de leer la señalización. En las sesiones de entrenamiento se experimentaron las prácticas de lectura, sin embargo, no había tiempo para hacer las reflexiones / mediaciones que permiten una expansión de su conocimiento, que se reproduce en el trabajo pedagógico, una relación ingenua acerca de la lectura. Por último, la formación aún no ha roto con la idea de que la lectura se aprende sólo con y para el placer, sin hacer hincapié en la necesidad de trabajar con las estrategias y las prácticas de la lectura para desarrollar las habilidades de los lectores, los profesores y sus alumnos.

Palabras clave: Lectura. Formación. La práctica en el aula.

\section{A AULA DE LEITURA E A LEITURA NA AULA}

Este $\operatorname{artigo}^{1}$ tem como objetivo analisar como as professoras-alfabetizadoras estabelecem as relações entre os estudos sobre leitura nas sessões de formação e em sala de aula. Nele, elegemos como objeto de estudo a leitura em sala de aula, considerando sua importância na escola e na vida, embora na escola, ainda não tenhamos encontrado as possibilidades necessárias para ensinar e que as crianças não só aprendam ler, mas que sejam leitoras.

Nessa trajetória, o governo brasileiro, desde os anos 2000, vem oferecendo Programas de formação continuada para os professores que trabalham nos anos iniciais do Ensino Fundamental, buscando melhorar a aprendizagem da leitura e da escrita, bem como reduzir as taxas de analfabetismo funcional existentes no país ${ }^{2}$. Para Alferes (2009), as razões para a criação de programas governamentais de formação continuada têm sido diversas, tais como: a) o nível de desempenho dos alunos a partir das avaliações realizadas em nível nacional; e b) a possibilidade de que, por meio, da formação continuada pode haver soluções para amenizar o baixo desempenho dos alunos e, consequentemente, a baixa qualidade da educação.

No conjunto das ações dos Programas governamentais para o desenvolvimento da Educação, no que se refere a alfabetização e a formação continuada, sempre é lembrado, pelos professores, o Programa de Formação de Professores Alfabetizadores (PROFA). Uma iniciativa

1 Integra dissertação apresentada no Programa de Pós Graduação em Formação de Professores da Educação Básica, nível Mestrado Profissional, na UESC, 2015.

$2 \mathrm{O}$ Brasil ocupa o $55^{\circ}$ lugar no ranking das médias de leitura entre os participantes do Programa Internacional de Avaliação de Alunos/PISA. Os dados foram divulgados no Relatório Nacional do PISA 2012 - Resultados Brasileiros. 
cuja abrangência atendeu o território nacional, por meio dos recursos técnicos e tecnológicos utilizados no desenvolvimento da proposta. Assim, com o PROFA, as ações de formação continuada aconteceram, de acordo com Alferes (2009, p. 13), de maneiras diversificadas, por meio dos "Parâmetros em Ação, programas de educação à distância (TV Escola, Formação pela Escola, Mídias na Educação e Universidade Aberta do Brasil - UAB), todos implementados pelo MEC nos últimos anos".

Para ampliar o conjunto das ações desses Programas governamentais, em 2012, foi criado o Programa Pacto Nacional pela Alfabetização na Idade Certa (PNAIC). Ao lançar tal programa, o Governo Federal, estabeleceu parcerias com os estados, os municípios e o Distrito Federal que, por sua vez, reafirmaram e ampliaram os compromissos previstos no Decreto 6.094/2007 (Compromisso Todos pela Educação), especificamente, no tocante ao inciso II do art. $2^{\circ}$, que indica a necessidade de "alfabetizar as crianças até, no máximo, os oito anos de idade, aferindo os resultados por exame periódico específico”(BRASIL, 2007, p. 1).

Com o PNAIC ampliou-se a abrangência da ação alfabetizadora, pois para cumprir seus objetivos, além de alfabetizar em Língua Portuguesa, devendo alfabetizar em linguagem Matemática. Além disso, as escolas participantes deveriam submeter-se a avaliações anuais, de caráter universal, realizadas pelo Instituto Nacional de Estudos e Pesquisa (INEP). Para tanto, seriam avaliados os conhecimentos adquiridos pelos alunos concluintes dos $2^{\circ}$ e $3^{\circ}$ anos do Ensino Fundamental, assim como as ações desenvolvidas pelo pessoal de apoio gerencial dos estados e dos municípios que aderiram ao PNAIC (BRASIL, 2012a).

As pesquisas que fundamentaram a construção do PNAIC mostraram que $15 \%$ das crianças concluintes do Ciclo Básico de Alfabetização não conseguiam interpretar um texto e realizar cálculos básicos (BRASIL, 2012). Tal fato fere o direito à Educação Básica de qualidade para todos os brasileiros. Ao nos referirmos ao direito à Educação, retomamos o direito preconizado pela sociedade civil e pela legislação de ensino, ou seja, referimo-nos à Lei 9.394/96, que estabelece as Diretrizes e Bases da Educação Nacional, e, no inciso I, do art. 32, enfatiza como meios básicos da educação o pleno domínio da leitura, da escrita e do cálculo (BRASIL, 1996).

É nessa perspectiva, então, que o PNAIC é considerado um conjunto integrado de ações, materiais, referências curriculares e pedagógicas disponibilizadas pelo MEC, tendo como eixo principal, a formação continuada de professores alfabetizadores. Sendo assim, o Programa estabeleceu parceria com as Instituições Federais de Educação Superior (IFES), que se tornaram responsáveis pela formação continuada a partir de quatro eixos: alfabetização, letramento, alfabetização matemática e organização do trabalho docente. 


\section{Leitura e a Formação do Professor (Leitor)}

No contexto em que vivemos, são exigidos práticas e usos sociais da leitura e da escrita. A todo instante deparamo-nos com imagens, textos, outdoors, panfletos, placas, letreiros. No entanto, ainda é grande o número de brasileiros que não conseguem adentrar nesse mundo da escrita e da cultura letrada. A permanência dessas pessoas fora do mundo letrado dá-se ou por não saberem ler, ou por não compreender a gama de leituras que são impostas no seu cotidiano.

A Escola é, por excelência, o espaço no qual as classes populares têm acesso ao texto escrito de forma problematizada. As atividades de leitura e escrita realizadas em sala de aula são, portanto, determinantes para o desenvolvimento da competência leitora, que "consiste na compreensão e no emprego de textos escritos e na reflexão pessoal a partir deles, com a finalidade de atingir as metas próprias, desenvolver o conhecimento e o potencial pessoal, e participar na sociedade" (PISA, 2003-2004, apud SOLÉ, 2012, p. 46).

Isso posto, é evidente a necessidade da formação do professor-leitor, o qual, por ser o responsável pelo ensino da leitura na escola, também vem sendo responsabilizado pelo fracasso ou pelo sucesso na formação do aluno leitor. Tratando-se da formação do professor leitor e da leitura como objeto de conhecimento, Solé (1998) enfatiza que estas devem entrelaçar as experiências de vida e as experiências profissionais do professor. Isso porque as leituras selecionadas para a sala de aula dizem também sobre suas crenças e convicções como ser individual e social.

Destarte, a leitura, como atividade cognitiva e social precisa ser ensinada e praticada, sistematicamente, na escola, levando-se em consideração os esquemas cognitivos que os alunos já trazem, seu repertório linguístico, os textos que falam, ouvem, veem e escrevem, nos mais diversos contextos em que estão inseridos.

Para Kleiman (1989, p. 10), "leitura é um ato social, entre dois sujeitos - leitor e autor - que interagem entre si, obedecendo a objetivos e necessidades socialmente determinados". À medida que o leitor vai decodificando as informações e vai conseguindo estabelecer relações entre o que está escrito e seus conhecimentos prévios, vai-se construindo o sentido e a compreensão se processa. Dessa forma, a leitura deve ser entendida como resultado de um trabalho anterior do autor e chega até o leitor convidando, desafiando a sua capacidade de leitura.

Desse modo, a leitura deve ser ensinada, e deve passar pelo processo da decodificação, para que o leitor consiga estabelecer relações entre as informações e os seus conhecimentos prévios, para que a compreensão se processe, pois, $o$ ato da leitura exige interações estabelecidas entre o 
leitor e o texto para a construção de sentidos (CAFIERO, 2005; KLEIMAN, 2011; 2013; SILVA, 2005; FOUCAMBERT, 1994; SOLÉ, 1998). Ler não é só dominar a mecânica de uma língua ou agrupar e separar letras, sílabas e palavras, embora esses procedimentos devam ser ensinados, tendo em vista os objetivos de leitura, mas, sobretudo, ler é interagir com textos, utilizando-se de diferentes estratégias na tentativa de construir significações para si, inclusive atribuindo novos sentidos que, necessariamente não foram pensados inicialmente pelo autor do texto.

Entretanto, é no âmbito pedagógico que se privilegia a avaliação da escrita pelos seus acertos e erros. Tal fato privilegia a prática escrita, relegando o segundo plano às atividades de leitura. A maneira como são tratadas práticas de escrita e de leitura contribuem para elevar os índices de crianças que, apesar de alfabetizadas, não conseguem compreender o que leem, pois apenas decodificam sem atribuir sentido, isto é, realizam leituras sem significar o que leem.

Aprender a ler envolve muito mais que percepções: ouvir, passar os olhos, ver. Ler é uma atividade de cumplicidade que requer envolvimento por parte daquele que lê e daquele que escreveu. Para o leitor esse envolvimento parece ser maior ainda, pois exige a capacidade de vivenciar a história, colocando-se como autor e/ou personagem. Foucambert (1994, p. 37-38) descreve três aspectos que deverão estar simultaneamente presentes desde o início do aprendizado da leitura:

- Aprender a ler com textos, não com frases, menos ainda com palavras, jamais com sílabas...

\begin{abstract}
- Aprende-se a ler lendo textos que não se sabe ler, mas cuja leitura se tem necessidade. Lê-los é procurar as respostas às perguntas que nos fazemos...-e, portanto, aprender a ler - é negociação entre o conhecido, que está na nossa cabeça, e o desconhecido, que está no papel; entre o que está atrás e o que está diante dos olhos. É um trabalho de detetive que utiliza índices (paginação, palavras conhecidas...) para elaborar hipóteses, verificá-las com base em outros índices, voltar aos pontos que permanecem obscuros, com ajudas externas, etc.
\end{abstract}

- As estratégias empregadas nesses atos de leitura serão analisadas e comparadas pelos diferentes atores que refletem sobre sua prática [...].

Assim, em sala de aula, é necessário que o professor-alfabetizador desenvolva práticas de leitura para que o aluno atribua sentido e compreenda o que está sendo lido. Os textos podem e devem atender as diversas finalidades: informar sobre um evento 
que interessa à turma, estudar e adquirir conhecimentos ou por simples prazer, por exemplo. Isso significa que, desde a educação infantil, quando as crianças ainda não leem convencionalmente, o professor estimula o desenvolvimento de uma postura de busca e elaboração de significados diante dos textos que circulam na escola e em seu cotidiano.

Tais ideias são corroboradas com os postulados de Solé (1998, p. 52) quando indica que "ler não é decodificar, mas para ler é preciso saber decodificar". A decodificação é, desse modo, uma parte importante da leitura que ajuda o leitor a estabelecer relações. À medida que ele vai decodificando as informações do texto, constrói unidades de sentido entre estas e os seus conhecimentos prévios, ou seja, processa a compreensão do que está sendo lido (CAFIERO, 2005). Neste sentido, os professores incentivam e trabalham com a leitura de forma sistematizada, desde os seus primeiros anos, para que percebam as habilidades de codificar e decodificar e a compreensão leitora como necessárias para se constituírem em um leitor que goste de ler, e se sintam capazes de realizar as atividades de leitura.

Nas salas de $1^{\circ}$ ano, foco dessa pesquisa, as atividades de leitura devem ser atividades de reflexão da língua, somente possíveis mediante a apropriação do texto pelo aluno. Kleiman (2013) exemplifica e nos leva à reflexão sobre se o leitor apenas identifica as letras. Ao solicitarmos a leitura de uma sequência, como - as estruturas - ele fará a leitura letra por letra, a-s-e-s-t-r-u-tu-r-a-s, e

[...] não conseguirá manter essas unidades na memória de trabalho, porque deverá esvaziar as primeiras letras na sequência quando a sétima, ou oitava, ou nona letra chegar à memória. Em termos de compreensão, ele não terá conseguido apreender essa sequência, não terá sequer lido as duas palavras, uma vez que as partes não se integram num todo significativo (KLEIMAN, 2013, p. 51).

Kleiman (2013) alerta que ao refletirmos sobre as práticas de leitura na escola, não percebemos seus objetivos ou propósitos. A falta de metas para a leitura nessa etapa da educação formal, em que as crianças, por não terem ainda os saberes necessários para realizar a leitura, tornam o ato de leitura uma tarefa entediante e árdua para o aspirante a leitor. Para a autora, é preciso levá-las a refletir sobre o processo de formação das letras em sílabas, de sílabas em palavras, de palavras em frases e em textos. A percepção de que existe uma forma convencional de escrita, 
a qual não pode ser modificada aleatoriamente, irá auxiliá-las no processo de decodificação, para formar palavras. $\mathrm{O}$ que, por sua vez, impossibilitará a atividade de leitura.

Desse modo, a escola deve assegurar a vivência de práticas concretas de leitura, ratificando a ideia, defendida por Kleiman (2013) e Solé (1998), entre outros, de que a prática de leitura na escola deve partir de um texto, que o leitor possa atribuir sentidos e tornar as informações obtidas significativas para sua vida. E a decodificação apenas não será suficiente para aprender a ler e a fazer uso social dessa ferramenta. A decodificação é um passo importante no processo de leitura, conforme expusemos anteriormente, no entanto, não se deve tomar a decodificação como única estratégia para o ensino da leitura. A consequência de um trabalho de leitura que não sai do nível da decodificação na aprendizagem do leitor é a impossibilidade desse sujeito adentrar no mundo da cultura letrada. Por isso, é essencial

(...) que sejam oferecidas condições para que as crianças entrem em contato com uma ampla diversidade de textos, em diferentes contextos de interação, para que possam ampliar capacidades comunicativas e, assim, utilizar a língua, buscando os efeitos de sentido pretendidos. (LEAL; MORAIS, 2006, p. 7)

Enquanto atividade social, o ato de leitura é complexo. Nesse contexto, Cafiero (2005) adverte que esse processo é mediado pela pertinência de conhecimentos prévios, imprescindíveis para que se estabeleçam as relações entre o que está sendo proposto e o que o aluno já sabe. Isso pressupõe que a leitura é uma atividade cognitiva e

[...] quando as pessoas leem, estão executando uma série de operações mentais que vão além da decodificação e utilizam estratégias, algumas inconscientemente e outras conscientemente. Como atividade social, a leitura pressupõe a interação entre um escritor e um leitor que estão distantes, mas que querem se comunicar. (CAFIERO, 2005, p. 08)

A esse respeito, Solé (1998) considera que durante a vida do indivíduo, há um acúmulo de informações e são construídas representações da realidade, graças às interações que são realizadas uns com os outros - principalmente com aqueles que exercem a função de educadores - e que, a cada momento da história esses conhecimentos são relativos e ampliáveis, auxiliando o leitor a compreender o texto. Destacamos, por isso, a contribuição de Freire (1989, p. 13), para quem a "leitura da palavra não é apenas precedida pela leitura do mundo, mas por uma certa forma de 'escrevê-lo' ou de 'reescrevê-lo', quer dizer, de transformá-lo por meio de nossa prática consciente". Com esta afirmação, o autor problematiza a noção de conhecimentos prévios, 
dizendo que estes se ampliam à medida que vivenciamos situações em nosso cotidiano, em que a leitura de mundo e a leitura da palavra mais que se associarem, complementam-se, completamse, se ressignificam e fazem sentido para o leitor. Desse modo,

Ler é uma operação inteligente, difícil, exigente, mas gratificante [...]. Ler é procurar ou buscar criar a compreensão do lido [...] ler é engajar-se numa experiência criativa em torno da compreensão. Da compreensão e da comunicação. E a experiência da compreensão será tão mais profunda quanto sejamos nela capazes de associar, jamais dicotomizar, os conceitos emergentes na experiência escolar aos que resultam do mundo da cotidianidade. (FREIRE, 1997, p. 20)

No caso dos professores que lecionam nos anos iniciais do Ensino Fundamental, para que eles tornem eficiente o uso social da leitura, é fundamental que proporcione momentos significativos de leitura, tornem-se modelos de leitores e fomentem a apropriação da linguagem escrita, ainda que os educandos desse nível de ensino não saibam ler convencionalmente. Sendo assim, o trabalho com a leitura deverá indicar suas finalidades e objetivos, propondo diferentes situações em que os alunos possam aprender a ler, construindo a sua autonomia leitora.

A formação do leitor (professor) para a leitura deve possibilitar o diálogo e a reflexão entre a teoria e a prática, entre os leitores e a prática pedagógica adotada pelo profissional docente, para que possa avançar em seus processos de formação leitora e para o ensino da leitura, isto é, para o desenvolvimento das habilidades e das competências leitoras e a aprendizagem e adoção de estratégias de ensino de leitura.

Tendo em vista que em sala de aula e na formação devemos lançar mão de diversas práticas de leitura para a formação do professor e dos alunos leitores, faremos, a seguir, uma breve apresentação conceitual de algumas dessas práticas. Cagliari (2001) refere-se às práticas de leitura presentes na escola e fora dela como 'tipos de leitura'. Entretanto, optamos por usar a nomenclatura 'modalidades de leitura', para que tipos de leitura não sejam confundidos com tipologia textual. São elas: a leitura deleite, a leitura colaborativa ou compartilhada, a leitura em voz alta ou oral, a leitura silenciosa ou visual, a leitura por alto e a leitura de imagem/leitura de livro de imagem.

Iniciamos com a leitura deleite que, de modo geral, é concebida como a leitura de textos literários. Trata-se de uma leitura associada a ideia equivocada, embora corriqueira, de que todo texto literário é fonte de entretenimento. Além disso, está também associada à concepção de que 
sua leitura implica numa reflexão sobre a vida. No Caderno de Formação do PNAIC, por exemplo, é caracterizada como uma estratégia formativa permanente, de dimensão, simultaneamente, lúdica e reflexiva:

Essa estratégia é muito importante nos processos de formação de professores alfabetizadores, pois favorece o contato do professor com textos literários diversos. O momento de leitura deleite é sempre de prazer e reflexão sobre o que é lido, sem se preocupar com a questão formal da leitura. É ler para se divertir, sentir prazer, para refletir sobre a vida. Tal prática, no entanto, não exclui as situações em que se conversa sobre os textos, pois esse momento também é de prazer, além de ser de ampliação de saberes. (BRASIL, 2012a, p. 29)

De acordo com a definição dada não se deve restringir a leitura deleite apenas ao universo literário, sendo possível, especialmente para os alunos, a leitura de textos de gêneros diversos. Isso porque se a leitura deleite está associada ao desenvolvimento do gosto pela leitura, é recomendável que o leitor compreenda que, em suas práticas sociais, o texto - literário e não literário - assume funcionalidades e sentidos amplos.

A definição apresentada pelo PNAIC indica a ausência de uma reflexão sobre o papel e a formação leitora do professor-alfabetizador. Sendo assim, a este profissional é atribuído o papel de despertar paixão pela leitura, como se o ato de ler fosse uma habilidade natural, inata do ser humano, sem quaisquer implicações sociais, ou seja, sem o ensino formal da leitura, pois para que o educando seja um leitor, de acordo com essa concepção, faz-se necessário apenas que o professor o estimule.

Assim, da mesma maneira que devemos levar em consideração o fato de que muitas crianças só têm acesso a livros de literatura ou a livros, de modo geral, na escola, devemos atentar para a necessidade de uma formação que se volte para os professores/leitores, para que oportunizem a aprendizagem e estimulem os alunos a ler textos (poesias, contos, fábulas, rótulos, manchetes) a dominar procedimentos próprios de um leitor experiente (que adéqua o tom de voz ao texto, dá ritmo a leitura, que pronuncia as palavras para produzir efeitos na recepção de quem ouve etc.), que sabe selecionar os textos de acordo com a situação, que tem conhecimento de estratégias de leitura para ler e tantas outras habilidades necessárias ao ato de quem lê para formar leitores.

A segunda modalidade é a leitura colaborativa, que é a compreensão textual mediante a interação entre aquele que lê - professor ou aluno - e aqueles que ouvem - professores e alunos. 
O professor que trabalha com o ciclo de alfabetização precisa entender que, nesse período, o aluno ainda não tem autonomia para realizar a leitura, entretanto, em colaboração com o outro, recupera ou dá sentido ao que é lido.

Na organização dessa modalidade de leitura, o professor deve ter clareza dos objetivos que quer alcançar e que se referem aos conteúdos que devem ser aprendidos. Sendo assim, os questionamentos que o docente deve fazer a respeito do texto, juntamente com a classe, recorrendo a estratégias antes, durante e depois da leitura (SOLÉ, 1998), as quais assumem a função de favorecer, instigar, levantar e comprovar hipóteses, argumentar, motivar, fazer inferências, relacionar a leitura com o contexto e os conhecimentos prévios e observar aspectos que não podem passar despercebidos para os educandos. O papel do professor é promover a busca de sentido, em um movimento de colaboração e mediação entre os leitores e a leitura.

Referindo-nos a leitura colaborativa, tal prática leitora tem características semelhantes ao que Solé (1998) denomina de leitura compartilhada, isto é, o desenvolvimento da compreensão leitora mediada pela formulação de previsões e perguntas sobre o que foi lido, o esclarecimento de possíveis dúvidas e um resumo sobre o texto. Para apresentar esse comportamento diante da leitura, o leitor se utiliza de estratégias, nem sempre conscientes, mas que se tornam explícitas quando o professor, ao planejar uma situação de leitura, tem como objetivo o ensino dessas estratégias.

A leitura colaborativa/compartilhada, por um lado, auxilia na compreensão do texto e, por outro, possibilita a aprendizagem sobre o uso de estratégias de leitura que serão necessárias, ao longo da formação leitora, para se tornar um leitor autônomo. A esse respeito, Solé (1998, p. 47) sugere que "se ensinamos um aluno a ler compreensivamente e a aprender a partir da leitura, estamos fazendo com que ele aprenda a aprender, isto é, com que ele possa aprender de forma autônoma em uma multiplicidade de situações".

No conjunto de modalidades de leitura, a leitura em voz alta ou leitura oral, comuns nas turmas em que as crianças não leem convencionalmente, como na Educação Infantil e no $1^{\circ}$ ano, em que ouvem as histórias lidas pelos adultos. Assim, "ouvir uma leitura equivale a ler com os olhos, a única diferença reside no canal pelo qual a leitura é conduzida do texto ao cérebro" (CAGLIARI, 2001, p. 156). O autor indica semelhanças e diferenças entre o processo de ouvir a leitura e ouvir a fala, a prosódia (seu ritmo, entonação, a cadência da leitura) é diferenciada entre a leitura e a contação de histórias, por exemplo. Isso porque a fala é espontânea e a leitura parte do que está escrito, porém o processamento fonético é o mesmo. Isso significa dizer que o 
educando decodifica e processa os sons que chegam aos seus ouvidos de modo semelhante nos atos de leitura e de fala.

Durante a leitura em voz alta ou leitura oral, como também durante uma conversa, o educando percebe os sons, examina as combinações das imagens acústicas e vai, aos poucos, atribuindo a cada conjunto de sons, isto é, às palavras, um conceito, de acordo com o conhecimento de mundo que possui. O leitor vai construindo, assim, os sentidos do texto oralizado, ainda que não de forma definitiva.

Para Solé (1998), a leitura oral ou em voz alta realizada na escola pretende verificar, de forma válida, se os alunos leem com clareza, rapidez, fluência, respeitando a pontuação e dando a entonação necessária. A autora alerta, contudo, para o equívoco de acrescentar a esta modalidade a exigência da compreensão do que foi lido. Isso porque para atender a esse objetivo, a leitura deveria acontecer de forma individual e silenciosa, precedendo a leitura em voz alta, com o aluno seguindo o seu próprio ritmo e elaborando sua compreensão. Inclusive, no caso dos alunos que estão na fase inicial do desenvolvimento da leitura, o professor deve dar pistas (por meio das gravuras, título do texto, levantando hipóteses, questionamentos), ensinando estratégias para que ocorra a decodificação e compreensão do texto lido.

Essa modalidade leitora deve ter objetivo claro e ser subsidiada por um planejamento. O professor pode, assim, ser um modelo de leitor para as crianças, além de oportunizar a ampliação do vocabulário e a apropriação da linguagem escrita antes mesmo de os educandos saberem escrever ou ler convencionalmente. Embora a leitura em voz alta venha sendo criticada por seu uso excessivo nas escolas, devemos refletir sobre essa prática, visto que nem sempre a leitura silenciosa será adequada para textos feitos para serem lidos oralmente ou mesmo escutados (CAGLIARI, 2001), isto é, os textos de tradição oral, tais como as cantigas de roda, poemas, parlendas e quadrinhas.

A quarta modalidade é a leitura silenciosa ou visual. Uma leitura que é realizada visualmente, sem o recurso da voz. Cagliari (2001, p. 156), apresenta vantagens em relação às outras pelo fato de não inibir o leitor "por questões linguísticas, como permite ainda uma velocidade de leitura maior, podendo ele parar onde quiser e recuperar paisagens já lidas, o que a leitura oral não costuma permitir". No entanto, no início do processo de aquisição da leitura, essa modalidade torna-se pouco produtiva. Além de não permitir a intervenção do professor, os alunos a realizam de forma fragmentada, por ainda não lerem convencionalmente. 
Nessa perspectiva, Kleiman (2013) lembra que o leitor inexperiente não compreende o texto durante a leitura, seja ela silenciosa ou em voz alta, mas somente no diálogo, que permite a discussão sobre o conteúdo e sobre os aspectos mais relevantes do texto. Para que haja a compreensão, é fundamental a interação com o outro e com o texto de forma sistematizada. Devemos avaliar, portanto, para que grupos e em que situações essa modalidade vai beneficiar o leitor ou colocá-lo à margem. Isso porque se o leitor não lê com autonomia, a leitura será uma atividade que gerará dificuldade ou mesmo se tornará impossível de ser realizada.

Ainda, entre as modalidades leitoras, a leitura por alto. Esta se caracteriza por ser uma leitura rápida, superficial de um ou vários textos. É realizada de forma silenciosa e individual, na qual o leitor busca a ideia chave ou o entendimento do texto como um todo, sem a preocupação de realizar uma leitura mais cuidadosa. Essa modalidade é comum nos encontros de formação e nas escolas, nas atividades em que são lidos fragmentos de um texto, um informativo etc.

Para Cagliari (2001) esta modalidade apresenta vantagens e desvantagens. Isso porque tanto pode conduzir o leitor a uma interpretação falsa do texto - se o conteúdo for desconhecido do leitor -, como também permite acelerar o processo de leitura, garantindo "uma compreensão razoável de um texto, inclusive no sentido de saber se vale a pena uma leitura mais cuidadosa ou não" (CAGLIARI, 2001, p. 160). Assim sendo, a leitura por alto é um ato que ajuda a ler um grande número de textos em um ritmo acelerado, sem profundidade e sem reflexões críticas.

A leitura de imagem/leitura do livro de imagem permite criar situações em que os personagens ganham vida de acordo com a vontade do leitor, sua inspiração, seus sentimentos. Segundo Manguel (2001) o que vemos e lemos de uma imagem se dá com base nas nossas experiências, ou seja, nos conhecimentos prévios que permitem fazer as relações e identificações e a leitura surge como a ação que permite explorar/ler a imagem, e esta pode nos capturar. Portanto, dois leitores fazendo a leitura de uma mesma imagem podem criar situações diferenciadas, podendo haver algo que seja comum, porém provocará diferentes efeitos de sentidos, pois o ato de ler é individual.

As imagens auxiliam na construção dos sentidos que serão diferentes de um leitor para outro, pois cada um leva para o texto/imagem suas experiências, seus conhecimentos. E nesse jogo entre o que nos olha e o que vemos, a leitura surge como a ação que nos permite explorar a imagem, "saboreá-la em seus diversos significados, criando distintas interpretações" (PILLAR, 2011, p. 17). 
Na leitura de imagem como elemento que auxilia a compreensão do texto e a construção de sentidos, deve-se ter o cuidado de não fazer qualquer leitura, pois o texto/imagem foi criado por alguém que quer comunicar algo e, portanto, devemos considerar "[...] todas as marcas do texto" (CAFIERO, 2005, p. 62) não apenas a imagem, mas objetivo/finalidade, seleção das palavras, organização das frases etc. As imagens auxiliam o uso das estratégias de leitura em que o leitor faz antecipações, cria hipóteses e/ou realiza inferências que serão verificadas durante e após a leitura ou com o passar das imagens.

As modalidades explicitadas caracterizam-se pelos objetivos de leitura, e o uso tem relação direta com sua finalidade. Quando se lê há um determinado objetivo, a partir do qual o leitor seleciona e utiliza estratégias diferentes para alcançá-lo. Essas são experiências primordiais para a formação de um leitor autônomo.

\section{Procedimentos Metodológicos}

Este artigo tem origem em uma pesquisa de abordagem qualitativa visto que permitiu uma compreensão do trabalho com a leitura em sala de aula, o que inclui as relações que estabelecidas com o conhecimento, o estudo e o desenvolvimento de sua práxis (BOGDAN; BIKLEN, 1982).

A pesquisa aconteceu numa escola municipal da cidade de Itabuna-BA, que funciona desde 2001, possui dez turmas do CIN - Ciclo da Infância - fases I, II e III, que correspondem ao $1^{\circ}, 2^{\circ}$ e $3^{\circ}$ anos respectivamente, sendo 2 turmas do CIN I e/ou $1^{\circ}$ ano, 4 turmas de CIN II ou $2^{\circ}$ ano, e 4 turmas de CIN III ou $3^{\circ}$ ano, distribuídas igualmente nos turnos matutino e vespertino.

Na sala do $1^{\circ}$ ano constavam livros de literatura em uma prateleira ao alcance das crianças e quatro caixas de livros do acervo de Obras Complementares do Programa Nacional do Livro Didático - (PNLD - MEC) $\left(1^{\circ}\right.$ ano) que ficavam em cima do armário. Cada professora recebeu duas caixas contendo, em média, 25 títulos cada e com gêneros textuais diferenciados, como contos, poesias, receita e etc.

As professoras-alfabetizadoras que participaram da pesquisa foram identificadas com nomes fictícios para preservar sua identidade e assinaram o Termo de Consentimento Livre e Esclarecido (TCLE). A professora do turno matutino, chamamos Lilás; e Rosa, a do turno vespertino. 
Para produção do material empírico da pesquisa, recorremos à observação nas sessões de formação do PNAIC realizadas com os professores-alfabetizadores e o acompanhamento nas salas de aula de Lilás e Rosa para observação das práticas de leitura e compreensão de como se estabelece a relação de aprendizagem do professor para trabalhar com leitura em sala de aula.

A observação possibilitou a escuta sensível das histórias e percursos formativos de Lilás e Rosa, nos seus espaços de trabalho, num exercício de nos afastar dos conceitos prévios e permitir que os sentidos estejam abertos à complexa realidade em que estivemos inseridos. Assim sendo, observamos seis sessões de formação e o Seminário de Avaliação do PNAIC, vinte e seis aulas das professoras Lilás e Rosa, para compreender como os conteúdos e as vivências da formação foram percebidos, interpretados e postos em prática pelas professoras-alfabetizadoras.

Realizamos a entrevista semiestruturada porque "ela permite a captação imediata e coerente da informação desejada, praticamente com qualquer tipo de informante e sobre os mais variados tópicos" (LÜDKE; ANDRÉ, 2013, p. 34) dando possibilidade ao pesquisador de realizar um diálogo individual com as professoras-alfabetizadoras, promovendo, assim, um conhecimento sobre o objeto de estudo, como também a possibilidade de rever os conceitos já estabelecidos.

Após a entrevista e a observação na formação e nas aulas, planejamos com as professoras sequência didática tendo como conteúdo a leitura, estudando e discutindo as estratégias de leitura (SOLÉ, 1998).

A leitura e a análise do material produzido na pesquisa exigiram habilidade e avaliação minuciosa e nesse movimento de leitura e impregnação destes dados, fomos questionando a relevância das informações que ajudaram a identificar aspectos que revelassem leitura na formação e na aula, e a contribuição no processo formativo para o trabalho nas salas de aula do $1^{\circ}$ ano. O material foi analisado em seu conjunto, considerando a leitura e as práticas de leitura em sala de aula.

\section{A leitura na formação e a aula de leitura}

Nas sessões de formação do professor-alfabetizador oferecida pelo PNAIC, acompanhamos várias situações de leitura que ora estava centrada na Orientadora de Estudos (OE - responsável pela formação), ora nos professores-alfabetizadores. O Gráfico 1 apresenta o 'lugar' da leitura na formação. 


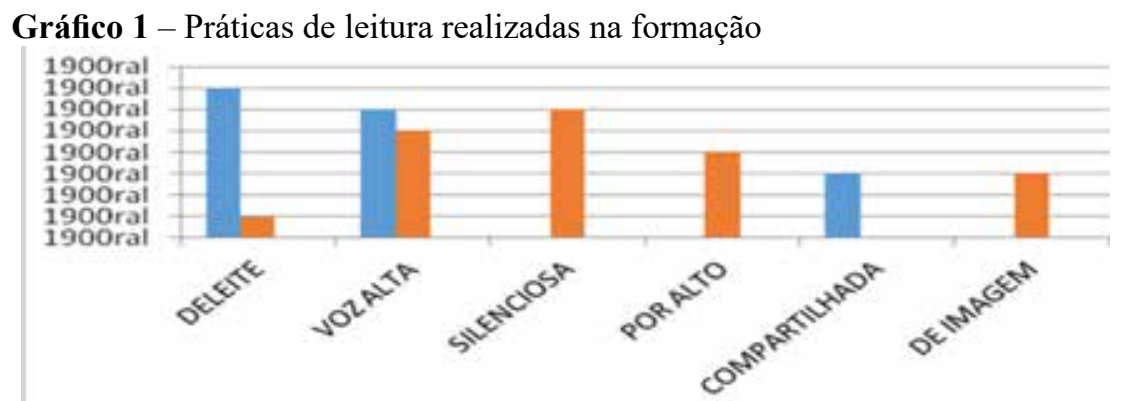

Fonte: Material produzido na pesquisa (2014)

Conforme os dados apresentados no Gráfico 1, a leitura deleite, em voz alta e a compartilhada ficaram centradas na OE. A leitura silenciosa, por alto, e a de imagem, era realizada pelos professores-alfabetizadores (PAs). Já a leitura em voz alta era revezada entre a OE e os PAs. As estratégias de leitura (SOLÉ, 1998) fizeram-se presentes em algumas situações, à medida que percebíamos a presença do levantamento de hipóteses, os argumentos e as inferências (antes, durante e após a leitura). Chamou-nos a atenção o fato de que, Lilás e Rosa terem vivenciado essas estratégias na formação, passaram a planejar aulas de leitura considerando-as como ponto de partida para o ensino da leitura.

Solicitamos que Lilás e Rosa descrevessem um momento em que aconteceu a leitura na formação, e este foi significativo para elas; disseram:

Eu me lembro da primeira leitura deleite que a formadora fez, que foi "Um minutinho só" de Ana Maria Machado; a forma com que ela foi lendo, foi mostrando um encantamento pela leitura, me chamou muito atenção e eu acabei fazendo com meus alunos do ano passado [2013] e repetindo esse ano [2014]. Percebi que eles gostaram também dessa leitura. Me marcou realmente, pela forma como foi feita, me encantou e chamou minha atenção. (Rosa, relato oral, 2014)

O vídeo "Os fantásticos livros voadores do Sr. Morris Lessmore" me fez pensar que sem a leitura você acaba não imaginando, você não desperta sua imaginação, a sua criatividade fica adormecida, chega um momento na sua vida que também se vê naquela situação, sem rumo, sem os livros, sem a leitura e o mundo que ela nos leva, então aquilo ali me fez despertar, porque minhas

2 Este vídeo encontra-se disponível no endereço: $<$ https://www.youtube.com/watch?v=LjkdEvMM5xs $>$ 
leituras agora são outras, muito técnicas do curso de Direito, diferentes das que eu fazia. Então foi bom retomar essas leituras infantis, da literatura infantil, lembrou minha época de criança, voltei a ler mais e agora faço sempre com os alunos. Esse vídeo me marcou bastante. (Lilás, relato oral, 2014)

A experiência de Rosa ao ouvir a leitura realizada pela OE foi significativa, fazendo com que selecionasse o mesmo livro para fazer a leitura no projeto da escola, e revivesse, com os alunos, o encantamento que a leitura proporcionou.

Nas sessões de formação, havia tempo para leitura e relato de situações vivenciadas em sala de aula, dos professores-alfabetizadores; porém, esse momento limitava-se à descrição da atividade, socialização de algum exercício ou texto, sem intervenção da $\mathrm{OE}$, discussão ou reflexão teórica acerca do que estava sendo relatado. Essa falta era justificada pela limitação do tempo, pois tinham que cumprir a carga horária da formação e a pauta pré-estabelecida.

A ausência de mediações nas atividades de leitura também foi percebida nas aulas de Lilás, momento em que a aluna Violeta (aluna - nome fictício) faz a leitura deleite do livro "Telefone sem fio", assim como na aula de Rosa, em que o aluno André (aluno - nome fictício) faz a leitura em voz alta da página solicitada. Neste artigo, apresentaremos a leitura de Violeta.

As mediações nas atividades em que os alunos leem, deveriam ser ações intencionais e planejadas, possibilitando a reflexão da leitura realizada e o avanço no processo de aquisição da leitura. Isso tornaria esta prática algo lúdico e construído numa troca constante entre as professoras-alfabetizadoras e seus alunos, ampliando o tempo dedicado a este tipo de exercício em sala de aula.

Durante a formação, Rosa e Lilás disseram que foram realizadas várias leituras e entre elas, a leitura de imagem, que lhes trouxe à memória experiências construídas ainda na infância e pouco presentes na sua sala de aula. Retomaram o trabalho com essas práticas de leitura, em um primeiro momento, para desenvolver atividades sugeridas na formação que, aos poucos, elas ganham vida e presença na sala de aula.

Nas aulas observadas, identificamos a presença da leitura de imagem e ilustrações em várias atividades, como na realização da leitura deleite e com o alfabeto dos animais. Na atividade de leitura deleite, Lilás e Rosa apresentavam as imagens ilustrativas para motivar e despertar o interesse das crianças pelo livro, ajudando a fazer previsões sobre o texto. 
Por ser uma atividade recorrente em sala de aula, observamos a aula, desenvolvida por Lilás em que Violeta realizou a leitura de um livro de literatura infantil a partir das imagens.

Lilás - Quem gostaria de contar esta história?

Era um livro intitulado "Telefone sem fio", de autoria de Ilan Brenman e Renato Moriconi. Um livro de imagens que retoma uma brincadeira tradicional (telefone sem fio), na qual uma palavra, frase, é cochichada no ouvido de alguém e esse passa adiante. A graça está no final: como chegará a frase que foi dita inicialmente?

Violeta, colocando-se de pé, respondeu (gritando entusiasmada): - Eu, tia... eu...

Lilás entregou-lhe o livro e solicitou que começasse a leitura.

E, após analisar a capa do livro, começou...

- Violeta: 'T' 'E' 'L' 'E' 'F' 'O' 'N' 'E' 'S' 'E' 'M' 'F' 'T' 'O'(leu letra por letra em voz alta).

Lilás - E aí, Violeta, qual o título do livro?

Violeta, observando a ilustração da capa respondeu: 'Abra Bem os Seus Ouvidos'.

Em seguida, abriu o livro e continuou a realizar a leitura das imagens:

O palhaço do rei sussurrou para o rei.

O rei sussurrou para o seu guarda.

O guarda sussurrou para o nadador.

O nadador sussurrou para o pirata.

O pirata sussurrou para a arara.

A arara sussurrou para o índio.

O índio sussurrou para o turista.

O turista sussurrou para uma nobre senhora rica. 
A senhora sussurrou para uma senhora pobre.

A pobre velhinha sussurrou para o lobo com o capuz de Chapeuzinho Vermelho.

O lobo vestiu a roupa da vovozinha e sussurrou a mesma coisa para Chapeuzinho Vermelho.

A Chapeuzinho sussurrou para o caçador.

O caçador sussurrou para o seu cachorro de raça.

O cachorro sussurrou para o palhaço do rei.

Fim

Após a leitura, Lilás solicitou que desenhassem as cenas de que mais gostaram do livro, entregando papéis em branco, disponibilizando lápis de cor e hidrocor para colorir a pintura.

Enquanto Violeta se organizava para realizar a atividade solicitada, aproximamo-nos para fazer algumas perguntas, conhecer melhor a pequena leitora e as estratégias que utilizou para a realização da leitura.

PESQUISADORA - Violeta, quantos anos você tem?

VIOLETA: Seis anos tia, faço sete em fevereiro (2015).

PESQUISADORA - Onde você ouviu essa palavra sussurrou? (a aluna repetiu a palavra sussurrou em todas as frases, num total de14 vezes).

VIOLETA: Na televisão.

PESQUISADORA: Você sabe o que é sussurrar?

VIOLETA: Falar baixinho, no ouvido. 
PESQUISADORA: Que imagem é essa, Violeta? (mostrando a imagem do livro)

VIOLETA: Um nadador.

PESQUISADORA: Como você sabe que é um nadador?

VIOLETA: Sim, tia, tem no desenho da TV, ele usa um capacete de respirador, igual a esse aí.

PESQUISADORA: (Mostrei a outra imagem) Por que essa senhora é uma "nobre senhora rica"?

VIOLETA: Ela usa óculos, colar de pérolas e a roupa dela é colorida.

PESQUISADORA: E essa aqui é uma pobre senhora, por quê?

VIOLETA: Essa é toda branca.

PESQUISADORA: (Insisti...) E por que essa é nobre e rica?

VIOLETA: Ela é toda loira, estilosa e bonita.

PESQUISADORA: E essa aqui é pobre?

VIOLETA: É pobre, não tem dinheiro e veste roupa feia, uma roupa sem cor, e a outra é colorida.

PESQUISADORA: E quem não veste roupa colorida é pobre?

VIOLETA: É, tia, sem cor.

PESQUISADORA: Você acha isso ou alguém falou para você?

VIOLETA: Minha mãe falou, eu também acho.

PESQUISADORA: Você conhece a história de Chapeuzinho Vermelho? 
VIOLETA: Hum rum...

PESQUISADORA: Onde você ouviu essa história?

VIOLETA: A história de Chapeuzinho Vermelho, minha tia do outro ano me contava, mas

eu já sabia algumas coisas, já vi no desenho que meu primo levou pra minha casa.

Durante a atividade com o livro 'Telefone sem fio', percebemos que Violeta ainda não lia convencionalmente. Na leitura do título leu letra por letra identificando-as, porém, ainda não conseguindo fazer a relação entre a letra, a sílaba e a palavra. Segundo Kleiman (2005), à medida que se processam as informações, o leitor vai armazenando-as em sua memória, para organizálas em unidades cada vez maiores, porém, Violeta ainda não consegue fazer esse processo de decodificação, ainda não tem o conhecimento da relação fonema-grafema, visto que leu o título como se fosse uma única palavra, sobrecarregando, assim, a memória de trabalho.

Violeta identificou as letras e leu o título segundo o que estava vendo na imagem. Durante a leitura, que realizou em voz alta para seus colegas, mobilizou seus conhecimentos prévios. O livro selecionado para leitura apresentava situações, por meio das imagens, que lhes eram familiares, pois tratava de temática que levava em conta seus conhecimentos prévios e favoreceu a ajuda necessária para construir o seu significado. Em relação a estratégia para aquisição da leitura, Violeta ainda se encontra na fase da pseudoleitura, criou frase para cada imagem que lia, porém sem encadeamento, tentando adivinhar o que cada figura correspondia (MOREIRA, 2003).

Embora, as imagens auxiliem o uso das estratégias de leitura para que o leitor faça antecipações, formule hipóteses e/ou realize inferências que serão verificadas durante e após a leitura ou com o passar das imagens (CAFIERO, 2005), tais ações não aconteceram com Violeta.

Fica claro na fala de Violeta, ao responder os questionamentos, que sua leitura é fruto das suas vivências, do que vem construindo enquanto experiências de vida, formativas, por meio dos filmes, de desenho animado que assiste na TV, dos diálogos com seus familiares, das suas interações e do conjunto de situações, inclusive as vivenciadas na escola, quando relata que já conhecia a história de Chapeuzinho Vermelho, pois sua professora, do ano anterior, havia lido para a turma. Essa experiência vivenciada somada a aprendizagem e aquisição da leitura convencional e autônoma podem fazer dela uma leitora ainda mais fascinante. 
Tal situação fez-se presente na leitura que Violeta traz para a escola. A leitura realizada na aula foi a do seu cotidiano, de suas vivências, quando expõe que aprendeu a palavra "sussurrou" e algumas características que ajudaram a identificar os personagens em programas de TV, assim como a suposição de que as pessoas se vestem com roupas coloridas são ricas etc.

Para Cafiero (2005, p. 38) o "escritor dá ao texto uma organização interna, pensa-o como um todo e não como uma soma de partes isoladas". Violeta leu as imagens e conseguiu elaborar frases soltas, que não tinha sentido para quem possivelmente pudesse vir a ler o seu texto. Construiu um texto com frases soltas, que ainda está presente na escola.

Em contrapartida, Lilás não realizou intervenção ou orientação no decorrer da atividade, e após o seu término apenas solicitou que os alunos desenhassem a parte de que mais gostaram, deixando o livro a disposição para quem quisesse folheá-lo. Esse é momento da aula em que o professor mostra aos alunos o que se ganha e o que se aprende com a leitura; e isso só é possível quando o professor realiza questionamentos e analisa as atividades, chamando a atenção dos alunos para aspectos que fazem parte do processo da leitura e da compreensão do texto, as hipóteses, inferências, as novas aprendizagens etc. recorrendo as estratégias de leitura (SOLÉ, 1998). Podendo, ainda, valorizar a transição entre a oralidade e a escrita (escrever o texto/frases no quadro), incentivando a participação de todos e mostrando que a oralidade e a escrita não são iguais. Momento esse que não fez parte da aula de leitura de Lilás, visto que na prática de sala de aula, a leitura do livro de imagem foi utilizada para narrar uma brincadeira (telefone sem fio) e, na formação a leitura de imagem foi utilizada para motivação e ilustração do texto do caderno de estudo. Nas duas situações, não avançou na compreensão leitora.

Entretanto, o uso de imagens é significativo para o desenvolvimento da competência leitora, e a inserção destas práticas em contextos de alfabetização, contribui ao desenvolvimento das habilidades necessárias a leitura, que pode ser realizada pelas crianças, inclusive as que ainda não leem convencionalmente. Isso possibilita o uso das estratégias de leitura uma vez que, à medida que observam as imagens, vão construindo hipóteses, realizando inferências que são verificadas na leitura posterior feita pela professora nos livros com textos escritos, assim como possibilita a produção de textos nos livros que possuem apenas imagens.

No processo de formação de Rosa e Lilás, as experiências com a leitura influenciam na prática pedagógica para alfabetizar os alunos, embora ainda permaneça a ausência de reflexão na prática em sala de aula limitando a ação e possibilidade de mediação do professor. Mas, identificamos nas práticas de leitura apresentadas na formação do PNAIC, as relações da 
experiência formativa com leitura e os estudos nos momentos de formação, percebendo as contribuições destas reflexões para o desenvolvimento de um fazer pedagógico crítico e reflexivo.

Assim, após as observações dessas situações de leitura, na formação e em sala de aula, planejamos, com Lilás e Rosa, sequência didática tendo como conteúdo a leitura e considerando as estratégias de ensino (SOLÈ, 1998) para ser realizada em sala de aula. O planejamento foi realizado com Lilás e Rosa no seu turno de trabalho.

O livro escolhido para realização da leitura em sala de aula, com os alunos foi "Quem vai ficar com o pêssego?", de Yoon Ah-Hae e tradução de Thais Rimkus. Inicialmente, discutimos o conceito de leitura, a leitura como processo e o conceito de leitura como atividade cognitiva e social (KLEIMAN, 2012; CAFIERO, 2005), as estratégias de leitura (SOLÉ, 1998; CAFIERO 2005), as pausas protocoladas (BRASIL, 2012; CAFIERO, 2005), além do direito à aprendizagem (BRASIL, 2012).

As atividades foram elaboradas a partir do livro escolhido, em consonância com os direitos de aprendizagem de Língua Portuguesa, cujos eixos são: Leitura, Produção de textos escritos, Oralidade, Análise Linguística. Os conhecimentos/capacidades apresentados nos eixos de Língua Portuguesa corroboravam o trabalho de leitura e suas estratégias de forma sistematizada e os demais conteúdos desenvolvidos nessa sequência didática.

Observando que nas aulas de Lilás e Rosa, nem sempre as estratégias de leitura - antes, durante e depois da leitura - e a mediação estavam presentes nas práticas de leitura com os alunos, foi feita uma discussão teórica para depois começarmos o planejamento da sequência didática. Apresentaremos uma sequência didática neste momento.

Durante o planejamento da sequência didática foi necessário a leitura do livro: "Quem vai ficar com o pêssego?" por mais de uma vez, para que pudéssemos selecionar os trechos, para o uso das pausas protocoladas. Percebemos que as pausas deveriam acontecer por três ou quatro vezes, pois o uso exagerado desse recurso poderia tornar a leitura muito extensa e cansativa. Para cada pausa foram planejados questionamentos que pudessem estimular a participação dos alunos, oportunizando que antecipassem, inferissem e levantassem hipóteses (SOLÉ, 1998) que seriam checadas no decorrer da leitura. 
A modalidade de leitura escolhida foi a "leitura compartilhada", pois o objetivo era desenvolver a compreensão leitora com uso das estratégias (antes, durante e depois da leitura), utilizando como base os direitos/objetivos de aprendizagem de Língua Portuguesa do eixo leitura.

O trabalho com a sequência didática, em sala de aula, foi realizado durante uma semana. Esta foi uma atividade que oportunizou a reflexão da prática pesquisadora e da prática alfabetizadora, num movimento revelador da práxis pedagógica.

Depois do trabalho desenvolvido, reunimos com Lilás e Rosa para a avaliação da sequência didática e das atividades desenvolvidas em sala de aula,

Nunca tinha trabalhado com a sequência de forma tão aprofundada, sempre tem outras coisas e a gente acaba pegando pouco, um trabalho superficial; nas escolas particulares que trabalhei, foi como se estivesse revivendo alguns momentos, acontecia em uma, duas semanas. Só que não consigo seguir a risca, mas planejo tudo, mas sempre vai ter mudanças, mas a gente tem um norte para as atividades. [...] o trabalho com a sequência dá um norte para as atividades com os alunos. Planejar o antes, durante e depois da leitura, isso pra mim foi novidade e teve um bom resultado, até os alunos dispersos que ficam conversando prestaram atenção na leitura e participaram.

[...] Pena que não deu tempo para fazer a receita ia ficar melhor ainda, mas quero experimentar na próxima sequência didática, fazer uma atividade diferente, sair da sala, eles [alunos] vão gostar. (Lilás, 2014)

Eu tentei seguir o planejamento da leitura, pra mim foi diferente, nunca tinha ouvido falar das pausas protocoladas. A leitura ficou mais interessante, eles compreenderam, prestaram mais atenção e aí fiz as pausas nas leituras deleite e achei que eles ficavam mais ligados na leitura, depois queriam comentar de tudo, a gente retomava. [...] as atividades de escrita, que também foram interessantes. Nunca tinha planejado uma sequência que trabalhasse Linguagem e Matemática juntas e ficou muito bom. Os alunos sempre queriam saber qual a atividade que a gente iria fazer. (Rosa, 2014)

A sequência didática faz parte da metodologia do PNAIC, porém ficou claro na fala de Rosa e Lilás, que ainda não tinham trabalhado com essa forma de organização do trabalho pedagógico. A sequência didática organizada com a leitura do livro "Quem vai ficar com o pêssego?" foi apresentada na formação e avaliada como uma atividade bem sucedida, tendo sido, inclusive, 
escolhida para ser apresentada no Seminário Municipal do PNAIC: Alfabetização Matemática em pauta, na cidade de Itabuna/BA, enfatizando o trabalho antes, durante e depois da leitura (SOLÉ, 1998), o uso das pausas protocoladas (CAFIERO, 2005; BRASIL, 2012) além dos direitos de aprendizagem de leitura na perspectiva do PNAIC (BRASIL, 2012).

Assim, incentivar a leitura na escola e em sala de aula tinha como finalidade apresentar o caráter interdisciplinar da leitura, ou seja, mostrar que na escola podemos ler em todas as áreas do conhecimento (Língua Portuguesa, Matemática, História, Geografia, Ciências, Meio Ambiente, Artes etc.). Os livros selecionados para planejar a sequência didática ajudaram-nas a avançar para além da leitura deleite que era realizada em sala de aula e com a possibilidade de trabalhar com mais de uma disciplina. O desenvolvimento da leitura aconteceu de forma significativa, mostrando as várias finalidades de um mesmo texto (deleite, fonte de informação, subsídio às atividades de escrita, oralidade e Alfabetização Matemática).

\section{Tecendo Considerações}

Com relação à experiência leitora de Lilás e Rosa, foi possível perceber que, embora digam ter uma experiência leitora, em sala de aula realizavam as leituras para cumprimento de tarefas. No entanto, como professoras-alfabetizadoras que ensinam crianças a ler e escrever, parece-nos que ainda não percebem a importância de serem leitoras. Em nossas conversas, deixaram clara a crença de que, oportunizando o acesso aos livros, já seria suficiente para realizar a tarefa de ensinar a ler.

Fica evidenciado que as sessões de formação despertaram o prazer pela leitura, que as professoras passaram a ler mais, voltando o encantamento e a magia que sentiam na infância. No entanto, não demonstraram uma visão mais crítica sobre a necessidade de eleger a leitura como objeto de estudo que lhes possibilitariam um conhecimento mais aprofundado a esse respeito, condição essencial para que se constituíssem como leitoras mais exigentes.

O trabalho com leitura realizado em sala de aula foi marcado pela empolgação de Lilás e Rosa, que se esmeraram para que seus alunos tivessem acesso aos livros. Passaram a planejar mais situações de leitura com os alunos, com momentos para manusear esses livros, fazer leitura de imagem, levantar hipóteses, realizar a pseudoleitura leitura (MOREIRA, 2003) etc. Estávamos findando o ano letivo e algumas crianças ainda estavam nos momentos iniciais da aquisição da leitura (pseudoleitura e decifração). 
As situações planejadas eram para promover as vivências leitoras com as crianças, utilizando livros infantis e criando situações de leitura. Na escolha dos livros, consideravam as preferências das crianças, oportunizando a realização da leitura, valorizando a participação de todos. Aceitavam as diversas formas ${ }^{2}$ de leitura utilizadas pelas crianças, que ainda não liam convencionalmente, realizando a pseudoleitura (MOREIRA, 2003). Essa prática das professoras foi fundamental na relação prazerosa que estabelecem com a leitura e como condição para aquisição da competência leitora.

A leitura em voz alta foi uma prática usada nas turmas de $1^{\circ}$ ano dessas professoras, aparecendo em diferentes momentos e contextos observados: sala de aula, pátio da escola e em casa. Além de ler para os alunos, as professoras-alfabetizadoras também oportunizaram situações para as crianças lerem para os colegas e família. Além disso, também apresentavam, em forma de reconto, as histórias lidas para outras turmas. O uso de diversas modalidades de leitura em suas práticas pode se constituir em uma experiência formativa, possibilitando a vivência de situações reais de leitura, contribuindo para a formação do leitor, pois proporciona ao sujeito uma aproximação com o universo da leitura. Assim, a formação do PNAIC contribuiu para construção da prática leitora para as professoras e para o desenvolvimento do trabalho com leitura com os alunos.

No entanto, essa pesquisa evidenciou que as professoras-alfabetizadoras não tinham uma prática sistematizada para a aquisição da leitura. Existia a crença de que o acesso e a vivência com os livros seriam suficientes para que as crianças aprendessem a ler. A ausência de reflexão sobre a leitura e o seu ensino impediam que realizassem as mediações necessárias para que as crianças avançassem na aprendizagem da leitura. Esse fato ficou claro nas aulas observadas e quando planejamos as sequências didáticas.

No desenvolvimento do trabalho com as sequências didáticas foi possível perceber que mesmo tendo um planejamento diferenciado, Lilás e Rosa trabalhavam as estratégias de leitura - antes, durante e depois (SOLÉ, 1998). Começavam o trabalho motivando as crianças para a leitura e realizavam as atividades propostas. No entanto, ainda não conseguiam retomar os caminhos seguidos pelos alunos nessas leituras (retomar as leituras, fazer questionamentos para verificar a compreensão, a pronúncia das palavras, a segmentação etc.). Esse fato ficou claro na aula em que Violeta, a aluna de Lilás, realizou a pseudoleitura (MOREIRA, 2003) do livro de imagem "Telefone sem fio", em que identificava as letras, mas não conseguia ler as palavras, fez a leitura do título como se fosse uma única palavra. Estas e outras situações, vivenciadas ao longo

3 Os alunos que não liam convencionalmente, liam as histórias a partir dos seus conhecimentos prévios e das imagens contidas no livro. 
da pesquisa, indicaram que ainda há certa lacuna em relação ao trabalho realizado com a leitura no processo formativo das professoras e na prática em sala de aula. Assim, o limite/lacuna da formação também se faz presente no trabalho dos professores em sala de aula.

Nas aulas de Lilás e Rosa observamos que as modalidades de leitura aconteceram em um conjunto, a opção foi pela leitura compartilhada. Entretanto, houve também a prática de leitura em voz alta, que não deixou de ser deleite, após o término, foi realizada de forma silenciosa pelos alunos com o auxílio das imagens e com a finalidade de desenvolver a compreensão leitora dos alunos.

Nas sessões de formação eram vivenciadas diversas modalidades de leitura. No entanto não havia o momento para fazer as reflexões/mediações que permitissem, às professorasalfabetizadoras, ampliar seu conhecimento a respeito desse objeto. Podemos perceber que as professoras acreditavam ter uma relação pessoal com a leitura, mas reproduziam, no trabalho pedagógico, uma relação ingênua. A formação ainda não rompeu com a ideia de que a leitura se aprende apenas com e pelo prazer, sem enfatizar a necessidade de um trabalho baseado nas estratégias e modalidades de leitura para ensinar as crianças a aprender a ler e para desenvolver as competências leitoras, tanto nas professoras, quanto nos seus alunos.

\section{REFERÊNCIAS}

ALFERES, Márcia Aparecida. Formação continuada de professores alfabetizadores: uma análise crítica do Programa Pró-letramento. 158f. 2009. Dissertação (Mestrado em Educação). Programa de Pesquisa e Pós-graduação em Educação. Universidade Estadual de Ponta Grossa, Ponta Grossa, 2009.

BOGDAN, R.; BIKLEN, S. Investigação qualitativa na educação: uma introdução à teoria e aos métodos. Portugal: Ed. Porto, 1994.

BRASIL. Lei n ${ }^{\circ}$ 9.394, de 20 de dezembro de 1996. Lei de Diretrizes e Bases da Educação

Nacional (LDBEN). Brasília, 1996. Disponível em: <http://www.planalto.gov.br/ccivil_03/leis/ 19394.htm>. Acesso em: 20 fev 2015.

Decreto n $\mathbf{n}^{\mathbf{6}}$.094, de 24 de abril de 2007. Disponível em:

http://www.planalto.gov.br/ccivil 03/_ato2007-2010/2007/decreto/d6094.htm Acesso em: 22 jan 2015.

. Portaria $n^{\circ} 867$, de 04 de julho de 2012. Diário Oficial da União. Seção 1, no 129. Pu-

blicado em 05 de julho de 2012. Disponível em: http://download.inep.gov.br/educacao basica/ 
provinha_brasil/legislacao/2013/portaria_n867_4julho2012 provinha_brasil.pdf Acesso em: 20 de fev 2015

- Ministério da Educação. Secretaria da Educação Básica. Diretoria de Apoio à Gestão Educacional. Pacto Nacional pela Alfabetização na Idade Certa: Formação do Professor Alfabetizador. Caderno de Apresentação. Brasília, MEC, SEB, 2012a.

. Ministério da Educação. Secretaria da Educação Básica. Diretoria de Apoio à Gestão Educacional. Pacto Nacional pela Alfabetização na Idade Certa. Currículo na Alfabetização: concepções e princípios. Ano 01. Unidade 01. Brasília, MEC, SEB, 2012b.

CAFIERO, Delaine. Leitura como processo: caderno do formador. (Coleção Alfabetização e Letramento). Belo Horizonte: UFMG, 2005.

CAGLIARI, Luiz Carlos. Alfabetização e Linguística. Scipione: São Paulo, 2001.

FOUCAMBERT, Jean. A leitura em questão. Tradução de Bruno Charles Magne. Porto Alegre: Artmed, 1994.

FREIRE, Paulo. Professora sim, tia não. Cartas a quem ousa ensinar. Olho d’Água. São Paulo. 1997. Paulo. 1989.

A importância do ato de ler: em três artigos que se completam. 23. Ed. Cortez: São

KLEIMAN, Ângela. Compreensão leitora. In: Glossário Ceale. Termos de alfabetização, leitura e escrita para alfabetizadores. Disponível em: http://ceale.fae.ufmg.br/app/webroot/glossarioceale/ verbetes/compreensao-leitora Acesso em 10 jan 2015.

Oficina de Leitura - teoria e prática. 15ª edição, Campinas, SP - Pontes Editora, 2013.

. Leitura: ensino e pesquisa. Campinas, SP: Pontes Editores, 2011.

Processos identitários na formação profissional: o professor como agente de letramento. In: CORRÊA, Manoel Luiz Gonçalves; BOCH, Françoise (Org.). Ensino de língua: representação e letramento. Campinas, SP: Mercado das letras, 2006.

LARROSA, Jorge. Notas sobre a experiência e o saber da experiência. In: Revista Brasileira de Educação. $n^{\circ}$ 19, Jan/Fev/Mar/Abr 2002.

LEAL, Telma Ferraz; MORAIS, Artur Gomes. A argumentação em textos escritos: a criança e 
a escola. Belo Horizonte: Autêntica, 2006.

MANGUEL, Alberto. A imagem como narrativa. In: Lendo Imagens. Uma história de amor e ódio. Trad. Rubens Figueiredo, Rosaura Eichemberg, Cláudia Strauch. São Paulo: Cia. das Letras, 2001.

MOREIRA, Cláudia Martins. Caminhos e oralidade: caminhos que se cruzam. In Letras de Hoje, Porto Alegre. V. 38, nº 2, junho 2003.

PILLAR, Analice Dutra. A educação do olhar no ensino das artes. 6 ed. Porto Alegre: Mediação, 2011.

SILVA, Ezequiel Theodoro da. Conferências sobre leitura. Campinas, SP: Editora Autores Associados, 2005.

SOLÉ, Isabel. Estratégias de leitura. Trad. Claudia Schilling. Porto Alegre: Artmed, 1998.

. Competência leitora e aprendizagem. Revista Ibero-Americana de Educação, $n^{\circ}$ 59, 2012. Disponível em: http://www.rieoei.org/RIE59.pdf Acesso em: 18.mar.2015. 